\title{
"So that's the way it is for me - always being left out." Acquired Pragmatic Language Impairment and Social Functioning following Traumatic Brain Injury
}

\author{
Jacinta M. Douglas ${ }^{1,2}$ \\ ${ }^{1}$ Living with Disability Research Centre, School of Allied Health, La Trobe University, Victoria, Australia \\ ${ }^{2}$ Summer Foundation, Victoria, Australia
}

\begin{abstract}
Our ability to interact appropriately in everyday interpersonal situations is fundamental to successful social integration. Impaired pragmatic competence correlates significantly and substantially with indices of social function across several domains for adults with acquired neurological disorders. In particular, evidence supports the negative impact of pragmatic impairments on the development and maintenance of relationships and community integration more generally.

Pragmatic language competence sits in a complex, multifactorial space characterised by interacting associations with cognitive and psychological functions and social and environmental parameters. This complexity is evident in much of the research seeking to unravel the nature and magnitude of interactions between pragmatic language competence and social outcomes in adults with acquired neurological disorders.

Over recent years our understanding of the impact of pragmatic impairments on social outcome has benefited substantially from inclusion of the insider's perspective in our research evidence base. Indeed, a methodological inclusion of constructivist paradigms has enabled the development of a rich understanding of the devastating social impact of impaired pragmatic competence.

The aim of this paper is to review pragmatic language impairment in the context of traumatic brain injury (TBI) and detail its impact on social functioning from the perspectives of people with TBI and their intimate partners/spouses and friends. With these perspectives as background, the paper concludes with consideration of therapeutic developments and a brief look at a novel intervention designed to reduce the negative impact of pragmatic deficits and improve functional language use following TBI.
\end{abstract}

Keywords: brain injury, pragmatic impairment, social function, relationship, couples, friends

\section{Introduction}

Pragmatic language competence sits in a complex, multi-factorial space characterised by interacting associations with cognitive and psycholog- ical functions and social and environmental parameters. Pragmatic skills have been variously described as 'the skills underlying competence in contextually determined, functional language

Address for correspondence: Prof. Jacinta Douglas, Living with Disability Research Centre, School of Allied Health, La Trobe University, Bundoora, Victoria 3086, Australia.E-mail: J.Douglas@latrobe.edu.au 
use' (Turkstra, McDonald, \& Kaufmann, 1995), 'the emergent consequence of interactions between linguistic, cognitive and sensorimotor processes which take place both within and between individuals' (Perkins, 2005) and 'the wide range of codified but subtle ways in which language use has evolved in a given culture' (Snow \& Douglas, 2017). Given its multifaceted nature, it follows that the study of pragmatic competence is inherently multidisciplinary (Cummings, 2005) covering scholarly endeavours across philosophy, linguistics, speech language pathology, cognitive science and psychology.

The multifactorial structure of pragmatic language competence is illustrated in Figure 1: 'A cup of competence' (Snow \& Douglas, 2017). This figure depicts the various constituent functions of pragmatic competence (executive, language and social cognition functions) conceptualised in the context of individual psychological characteristics as well as social-environmental influences. As a result of this complexity, there are many levels at which skills can be compromised giving rise to substantial challenges for the reliable and valid assessment of pragmatic impairment (for review see Cummings, 2017; Douglas \& Togher, 2017).

Pragmatic deficits are encountered in a range of neurological conditions including those associated with focal damage (e.g., unilateral stroke, both right and left hemisphere); those associated with more diffuse damage (e.g., traumatic brain injury (TBI); as well as degenerative disorders (e.g., Alzheimer's disease, variant forms of primary progressive aphasia) (for review see Douglas \& Togher, 2017; Snow \& Douglas, 2017). Each of these acquired neurological disorders affects a substantial proportion of the adult population. In Australia alone our prevalence rate of $2.2 \%$ (Australian Institute of Health and Welfare, 2007) means that one in 45 Australians are living with brain injury related disability and almost three quarters of these people are less than 65 years of age.

Lack of social integration and poor quality of social relationships are common and enduring experiences for many people who acquire neurological disorders during adulthood (Barry \& Douglas, 2000; Clare et al., 2012; Galski, Tompkins, \& Johnston, 1998; Lefebvre, Cloutier, \& Levert, 2008; Pound, Gompertz, \& Ebrahim, 1998). Further, increasing evidence demonstrates that disorders likely to be associated with negative social outcomes are those that involve changes in the functional use of language (Douglas, 2015; Hilari et al., 2010). Over recent years our understanding of the impact of these acquired pragmatic impairments on social outcome has benefited substantially from inclusion of the insider's perspective in our research evidence base. Indeed, a methodological shift to constructivist paradigms has enabled the development of a rich understanding of the devastating personal experience of impaired pragmatic competence and its impact on social living.

The aim of this paper is to review pragmatic language impairment in the context of evidence in the field of TBI, describe its impact on social integration particularly within relationships from the individual perspectives of those with TBI and their intimate partners/spouses and friends. The paper concludes with consideration of therapeutic developments and a brief look at a novel intervention designed to reduce the negative impact of pragmatic deficits and improve functional language use following TBI.

\section{Understanding the Personal Experience: Theory, Practice and Research}

Many scholars have emphasised the personal significance of the interplay between the individual and society. Notable among these theorists are those working in the tradition of symbolic interactionism, considered to be one of the most enduring social theories of the 20th century (Benzies \& Allen, 2001; Oliver, 2012; Plummer, 2000). Symbolic interactionism views the individual and the context in which the individual exists as inseparable and mutually constructed in the course of social interactions. George Herbert Mead's (1863-1931) theory of the emergence of mind and self out of the social process of communication is generally considered the foundation of symbolic interactionism. Mead described the individual as 'taking the attitudes of other individuals toward himself (sic) within a social environment or context of experience and behaviour in which both he and they are involved' (1934, p. 203). Thus, from Mead's view, it is the individual's perception or interpretation of his/her own social world that influences the self.

Herbert Blumer (1900-1987), Mead's student, progressed the tradition of symbolic interactionism during the mid 20th century stating:

\footnotetext{
The term "symbolic interactionism" refers of course to the peculiar and distinctive character of interaction as it takes place between human beings. The peculiarity consists in the fact that human beings interpret or "define" each other's actions instead of merely reacting to each other's actions. Their "response" is not made directly to the actions of one another but instead is based on the meaning which they attach to such actions. Thus, human interaction is mediated by the use of symbols, by interpretation, or by ascertaining the meaning of one
} 


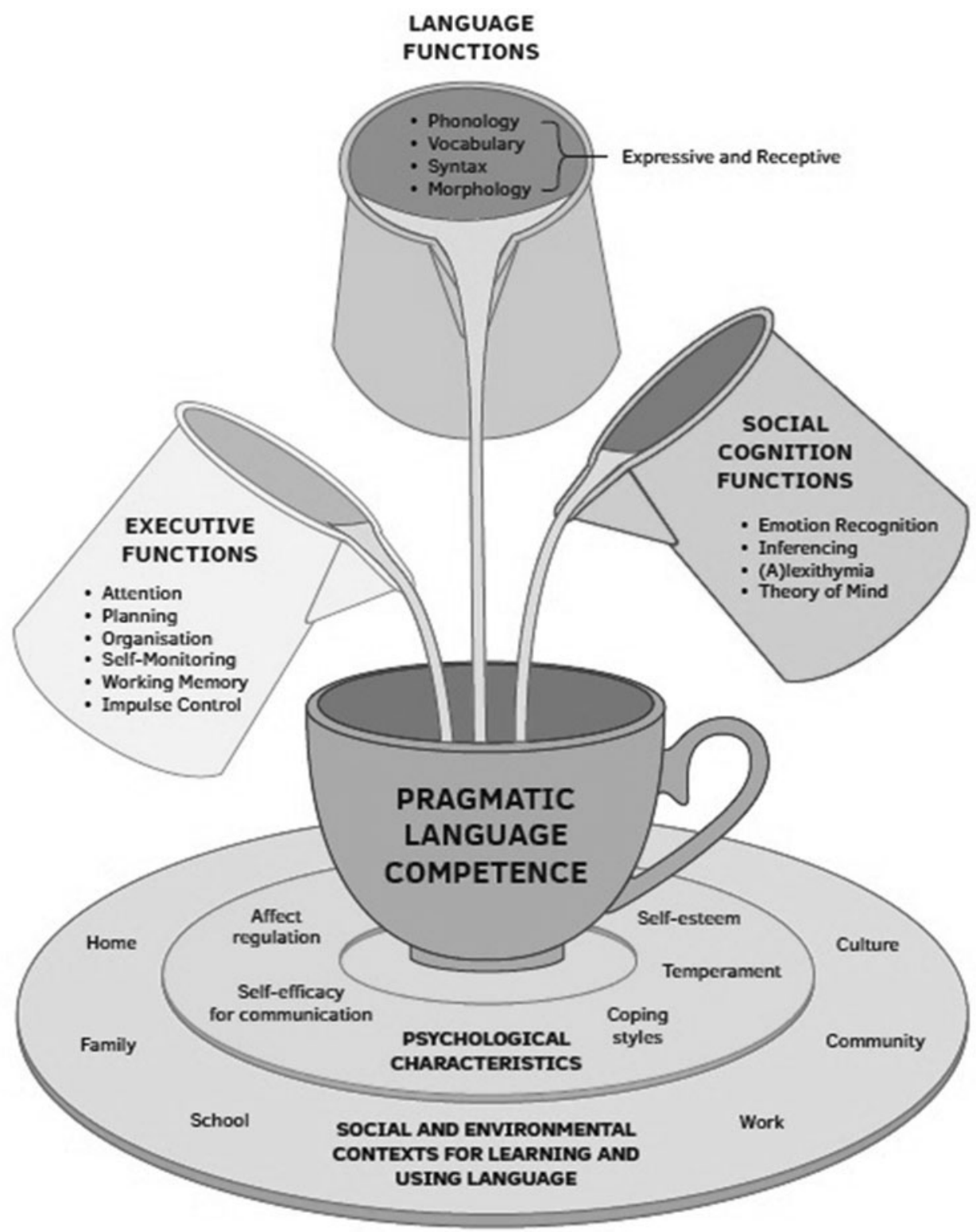

\section{FIGURE 1}

'A cup of competence': Constituent functions of pragmatic language competence and psychological and social influences. From Research in Clinical Pragmatics Volume 11 of the series Perspectives in Pragmatics, Philosophy \& Psychology, Chapter 23, Psychosocial Aspects of Pragmatic Disorder, 2017, pp 617-649, Snow \& Douglas. With permission of Springer Nature.

another's actions. This mediation is equivalent to inserting a process of interpretation between stimulus and response in the case of human behavior." (Blumer, 1962, p. 180).
Blumer $(1962,1969)$ went on to outline important tenets underpinning this theoretical stance. He described individuals as acting toward people and things based upon the meanings they have given to 

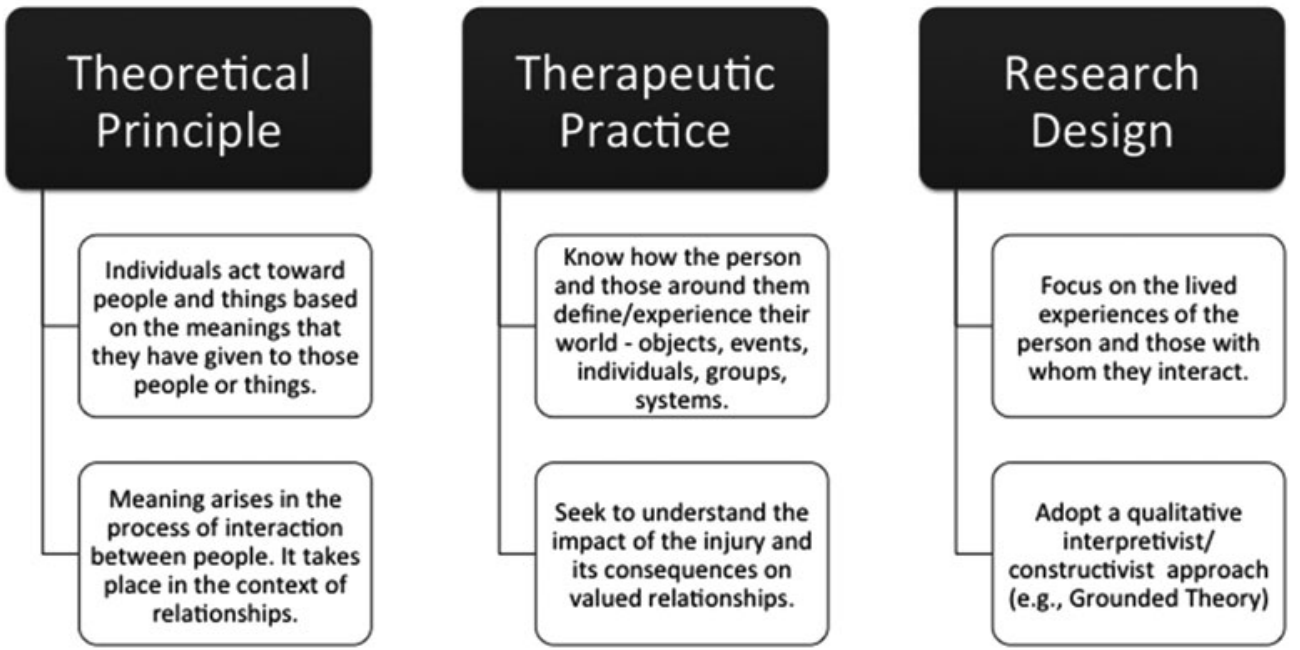

\section{FIGURE 2}

Rehabilitation and research implications of symbolic interactionism.

those people or things. Thus, meaning arises in the process of interaction between people; it is a social process taking place in the context of relationships. In turn, people are assumed to have the capacity to negotiate meaning through symbols giving rise to an interpretive process that is ever changing. In other words, he described human behaviour as emergent and continually constructed. Within this framework then, it can be seen that pragmatic competence, involving the use and interpretation of codified signs, makes a direct contribution to meaning as constructed within the interaction.

The theoretical tenets of symbolic interactionism have some important implications for practice within therapeutic or rehabilitation and research domains (Douglas, Drummond, Knox, \& Mealings, 2015) (Figure 2). In rehabilitation, appreciating the client's experience requires the clinician to understand the meaning of the situation from the perspective of the injured individual and those with whom the individual relates. In a symbolic interactionist framework, understanding cannot be fully developed based on what is typically captured through test administration; it requires shared interactions with the injured individual and close others and direct consideration of the role/s valued by that individual. In short, viewing the world as much as possible from the client's perspective. Similarly in the domain of research, symbolic interactionism demands the use of constructivist interpretivist approaches with a focus on exploring the lived experience of the person with injury and those with whom they interact.

\section{Exploring Pragmatic Deficits in the Context of TBI}

Globally TBI will surpass many diseases as the major cause of disability by 2020 (Hyder, 2007). As many as $70 \%$ of these people will report difficulties with communication including motor speech impairment (Wang, Kent, Duffy, \& Thomas, 2005), word finding problems (Bittner \& Crowe, 2006; Olver, Ponsford, \& Curran, 1996), comprehension difficulties (Olver et al., 1996) and pragmatic impairment (Channon \& Watts, 2003; McDonald, 1993; Snow, Douglas, \& Ponsford, 1997, 1998; Turkstra et al., 1995). Further, longitudinal studies demonstrate that these communication deficits, particularly in the domain of pragmatics, persist into the long term and result in substantial ongoing demands on therapy resources (Snow et al., 1998). In fact data from one of our early studies showed that problems in conversation continued to be evident in $96 \%$ of speakers with moderatesevere TBI who were followed up over 2-years, despite having had considerable therapy (Snow et al., 1998).

While incidence and prevalence statistics illustrate the scope of the problem, personal description powerfully evokes the experience of pragmatic impairment faced by people with TBI everyday as they go about negotiating life in social settings. Table 1 presents a summary of quotes from research participants outlining the pragmatic communication behaviours that they perceive as challenging (Bracy \& Douglas, 2005; Douglas, 


\section{TABLE 1}

The Personal Experience of Pragmatic Deficits

\begin{tabular}{ll}
\hline Personal Experiences" & Pragmatic Problems \\
\hline $\begin{array}{l}\text { What the hell do I say? I don't know, so I don't speak } \\
\text { I do have problems starting up a conversation . . specially when it comes }\end{array}$ & Generating topics \\
to women & Initiating conversation \\
I don 't say the right thing - I say ridiculous things & Inappropriate comments \\
I go on and on about things, I don't know when enough's enough & Verbosity \\
I can't seem to pick up even their facial expressions or their voice to know & Reading non-verbal cues \\
when to say something or even if I should say something & \\
I don 't seem to show people I' $m$ interested in what they ' re saying & Using non-verbal cues \\
$\begin{array}{l}\text { You've got to be trying to think about two things, that you're actually doing } \\
\text { the actual communication stuff, but then at the same time remember the } \\
\text { stuff you're saying }\end{array}$ & Simultaneous pragmatic and \\
\end{tabular}

\#Note: Participant quotes from (Bracy \& Douglas, 2005; Douglas, 2010; Douglas, 2015; Mackey et al., 2007; Shorland \& Douglas, 2010).

2010; Douglas, 2015; Mackey, Sloan, Starritt, \& Douglas, 2007; Shorland \& Douglas, 2010). These quotes show that people with TBI are well aware of the functional communication challenges they grapple with on a daily basis ranging from knowing what to say, when and how to say it, and keeping track of the interaction. Given the enormous challenges so effectively captured by these statements, it is unsurprising that many people with TBI experience social interaction as an anxiety provoking activity: 'I get so anxious ... there's so much happening, I never knew' (Michael) (Douglas, 2015, p. 207).

The consequences of impaired communication skills following TBI are also well illustrated across several studies that have directly investigated the association between functional use of language and community integration (Dahlberg et al., 2006; Galski et al., 1998; Snow et al., 1998; Struchen et al., 2008; Struchen, Pappadis, Sander, Burrows, \& Myszka, 2011). Although these studies show variable findings with respect to the magnitude of the association, they generally yield modest to strong statistically significant correlations accounting for as much as $18.5 \%$ of variance in community integration scores.

Snow et al. (1998) reported that clinician-rated discourse errors correlated significantly with $(r=$ $-0.36, p=.04$ ) and accounted for $13 \%$ of the variance in social integration scores as measured by the Craig Handicap Assessment and Reporting Technique (CHART; Whiteneck, Charlifue, Gerhart, Overholser, \& Richardson, 1992) in a group of 26 adults with severe TBI followed up 2 years after injury. In that same year, Galski et al. (1998) reported similar findings between clinician-rated discourse parameters and the CHART ( $r$ ranging from .06 to .41 ) in a group of 30 participants with mod- erate to severe injuries. More recently, Dahlberg et al. (2006) showed that self-rated but not close other-rated social communication ability was significantly associated with social integration in a group of 60 participants with moderate to severe brain injury sustained 1-21 years previously. Correlation coefficients between self-rated social communication abilities and both the CHART and the Communication Integration Questionnaire (CIQ; Willer, Ottenbacher, \& Coad, 1994) ranged from 0.28 to 0.43 . In 2011, Struchen et al. reported the findings of their evaluation of the contribution of self-rated social communication skills ( $\mathrm{La}$ Trobe Communication Questionnaire (LCQ) selfreport; Douglas, Bracy, \& Snow, 2007; Douglas, O'Flaherty, \& Snow, 2000) to prediction of social integration outcomes (CIQ) using hierarchical multiple regression on data from 184 adults with TBI at least 6 months after discharge from acute care. After accounting for demographic and injury-related characteristics, social communication and affective/behavioural variables accounted for a statistically significant amount of variance in social integration functioning. Social communication measures accounted for $11.3 \%$ of the overall explained variance in social integration and the LCQ total score made a statistically significant and unique contribution to the prediction of CIQ scores.

Significant association between communication and social participation can be expected given that communication is the means by which we negotiate daily activities and relationships. Indeed, interpersonal communication skills contribute to vocational outcome in their own right, separable from the contribution made by executive cognitive function (Struchen et al., 2008). In addition, while executive control processes influence social communication competence, they do not explain 
pragmatic deficits and research shows that executive function measures leave a substantial proportion of variance (almost two thirds) in pragmatic impairment unexplained (Douglas, 2010).

\section{The Experience of Pragmatic Deficits Within Relationships}

\section{Friendships}

Friendship is characterised by mutual help and support. Willmott (1987) defined a friend as someone you can trust, someone whose company you enjoy, and someone with whom you can discuss things freely. Friends typically have similar attitudes, beliefs and interests (Nussbaum, 1994). They also demonstrate similar values concerning communication (Burleson, Samter, \& Lucchetti, 1992). In particular, Burleson et al. (1992) found that pairs of friends rated the ability to 'comfort' as a communication skill important to maintaining their friendships. Thus, it can be anticipated that negative changes in a person's communication behaviours, especially those that convey mutuality and sensitivity, will have a negative impact on existing friendships. Further, if a person's communication behaviours reflect socially inappropriate behaviour, that person's ability to develop new friendships is likely to be reduced (Snow \& Douglas, 2017).

The negative impact of changed pragmatic competence on friendship after TBI has been highlighted by the findings of several qualitative studies (Karlovits \& McColl, 1999; Paterson \& Stewart, 2002; Shorland \& Douglas, 2010)). People with TBI identified social interaction as one of nine sources of stress in Karlovits and McColl's (1999) study. They described feeling that they no longer had ownership over what and how they contributed to conversations:

At times I tend to monopolize the conversation.

I'm trying to keep an eye on that. I'd be roughly corrected in the past and I realize it doesn't win too many friends (Karlovits \& McColl, p. 852).

Paterson and Stewart (2002) analysed focus group data from 11 participants deriving themes relating to how participants viewed their interactions and relationships. Participants linked lost friendships with their changed communication: 'When you go somewhere, aye, they look at you, 'oh he's alright.' And as soon as you speak, it all flips over one side' (Paterson \& Stewart, 2002, p.16). They identified strain on their day-to-day interactions particularly due to lost or reduced ability to be tactful: 'You just say straight away what you want, there is no tactfulness involved' (Paterson \& Stewart, 2002, p.16).
In 2010, we (Shorland \& Douglas, 2010) highlighted similar difficulties in the experiences of two young adults, Rachel and Dave, following severe TBI. Three key themes emerged from analysis of the in-depth interview data: evolution of friendships following TBI; perceptions of communication; and opening up to others. The participants' perception of their ability to communicate contained many examples of their experiences of impaired pragmatic competence. Rachel commented on difficulties with interpreting turn-taking cues, leading to her tendency to interrupt:

Sometimes I have trouble if someone's speaking and I'm not quite sure when they've finished, like if they have a pause for a moment and then I want to go and say something but they actually haven't finished saying something so I butt in (Shorland \& Douglas, 2010; p. 574).

Rachel also remarked on problems with managing discourse structure and difficulties modifying prosody to convey emotional tone:

Sometimes I start with saying something then I go back to the beginning of what I should be actually saying to make, make more sense in my mind but I'm sort of speaking that out loud; I suppose I try and correct it [disjointed discourse] as best as possible. But yeah it happens sort of as I'm, as I'm speaking because my brain doesn't sort of do it beforehand like un-brain injured people's brains.' ... 'She [friend] could tell by what I was saying that I was sincere, but not by the tone of my voice. (Shorland \& Douglas, 2010; p. 574).

Both Rachel and Dave highlighted difficulties with managing their contributions to conversations:

I had trouble with continuing a conversation. You say 'hi how are you' and then where do you go from there? (Rachel). (Shorland \& Douglas, 2010; p. 574).

.... sometimes I sort of run out of things to say and then, then sort of the other person doesn't, bring anything new into the conversation, you sort of get stuck (Dave). (Shorland \& Douglas, 2010; p. 574).

Approaching someone, initiating, is a little like strange, or unfamiliar to me and bringing conversations to a close I don't always know how to, how to end a conversation or how to leave a conversation in a, in a correct manner ... (Dave). (Shorland \& Douglas, 2010; p. 574).

Although Rachel acknowledged that her communication might affect her friendships: 'So the way I speak to people and communicate with them I suppose would affect the friendships that I have and am trying to make' (Shorland \& Douglas, 2010; p. 574), she was surprised when her 
friends discussed changes in her communication that could impact the quality of their relationships: 'I think it's the same but [my friends] were telling me things that they noticed that my communication is different ... When they were telling me these problems, it made me feel a bit disheartened, a bit miserable.' (Shorland \& Douglas, 2010; p. 574). Dave described the impact of his communication difficulties on relationships by reference to his lack of confidence: 'Confidence is a big issue, when it, when it goes to walking up and talking to someone' (Shorland \& Douglas, 2010; p. 574). His response is consistent with evidence that people with TBI take a passive role in conversation (Bogart, Togher, Power, \& Docking, 2012). Dave described himself in this manner but also noted that his passivity varied according to particular communication partners and settings. Finally, both Rachel's and Dave's experiences supported the importance of addressing the communication difficulties of this population using context-specific approaches that include social activities with friends and peers.

\section{Intimate Relationships}

Acquired communication impairments impact on relationships in general, and most significantly, on intimate spousal/partner relationships. Sustaining emotional intimacy in partner relationships relies on dialogue, transparency, vulnerability, and reciprocity (Perlman, 2008). Indeed, relational problems in couples have been conceptualised as a function of deficiencies in communication skills, resulting in dyadic distress and dissatisfaction (Rogge \& Bradbury, 1999). As two-way conversations are the currency for sustaining intimacy in healthy partner relationships (Duck, 1988), negative changes in pragmatic ability are likely to threaten the spousal bond. Evidence to support this contention can be found in the literature examining the experience of couples following TBI (Bracy \& Douglas, 2005; Gill, Sander, Robins, Mazzei, \& Struchen, 2011; Godwin, Chappell, \& Kreutzer, 2014; O'Flaherty \& Douglas, 1997).

Individuals with TBI frequently struggle within intimate relationships as a result of communication challenges, information processing difficulties, and frequent emotional and sexual intimacy issues (Godwin et al., 2014). Similarly, their partners also experience communication difficulties as barriers to intimacy. Gill and colleagues (2011) interviewed 18 couples at a mean length of 4.78 years post-injury. Most participants identified good communication as critical to maintaining their intimate relationship and negotiating the injury related changes they encountered. Partners noted that communication seemed to take place on a different level after TBI, with conversations lacking intellectual and emotional depth: 'I think an intimate moment is when you pour your heart out. And we can't do that anymore' (Gill et al., 2011, p. 62). Some also reported that their injured partner tended to avoid discussing issues that affected the relationship. Bracy and Douglas (2005) also noted topic avoidance in their study of couples following TBI. However, avoidance tended to be used as a coping strategy by partners to steer clear of topics that were likely to trigger negative, difficult or angry interactions.

Using a model of interpersonal communication, O'Flaherty and Douglas (1997) explored the subjective experience of living with the consequences of TBI. The married participants in the study described fundamental changes to the dynamics of their relationship as a couple. Participants reported a substantial decline in social and leisure activities, with married dyads reporting a progressive tendency for the uninjured spouse to socialise alone. Participants identified increased tension in situations in which wider family and/or friends were together as one of the reasons for this outcome. Further, the injured partner's unpredictable and inappropriate communication was seen as the source of this tension for spouses, while injured partners reported feeling unable to 'keep up' in fast-moving and busy social situations, and therefore consciously chose to avoid them: ' . . . as I said I just don't go [to social activities at his wife's workplace] because I'm more of a hindrance or make it harder for her to enjoy herself' (O'Flaherty \& Douglas, 1997, p. 900).

Spouses also identified insensitive or violent outbursts, and difficulties with implicature and social banter as particularly challenging in their relationships:

. . . it's still very hard when someone's screaming and shouting at you (O'Flaherty \& Douglas, 1997, p. 901).

... you know, if there's a trick in it. And she just won't get it. Won't get it; Some of the problem with friends ... part of the friendship was always banter. Banter that you used to .... and you [directed at injured partner] can't keep up with that now ... You know jokes and asides (O'Flaherty \& Douglas, 1997, p. 903).

Evidence not only in the TBI literature but also in the stroke (Bakas, Kroenke, Plue, Perkins, \& Williams, 2006; Grawburg, Howe, Worrall, \& Scarinci, 2013) and dementia (Eloniemi-Sulkava et al., 2002; Pozzebon, Douglas, \& Ames, 2016) literature shows that intimate relationships are vulnerable to pragmatic impairments that result in even subtle changes in interpersonal 
communication. Further, these changes can progressively erode the fabric of a couple's relationship and pose a direct threat to the cohesion of that relationship. Consequently, it is important that we focus therapeutic attention on pragmatic competence, particularly in the context of intimate partnerships.

\section{Communication Rehabilitation Following TBI}

Despite the overwhelming negative impact of communication disability after TBI, high quality evidence to inform clinical management of this problem continues to be relatively scarce. To date only five randomised controlled trials (RCTs) of communication rehabilitation for adults with TBI have been published. In 2014, the international recommendations for management of cognition following TBI (INCOG guideline) (Bayley et al., 2014) included seven recommendations regarding best practice for the assessment and management of communication disorders following TBI (Togher et al., 2014). Only three are based on evidence from at least one randomised trial with a relevant control group. Evidence currently available supports the effectiveness of context-sensitive interventions embedded in the person's everyday life, communication partner training, and metacognitive strategy training (Togher et al., 2014).

We have recently developed and completed preliminary evaluation of a new approach to intervention for communication disability (Douglas, Knox, De Maio, \& Bridge, 2014; Douglas et al., in press). This approach focuses on coping in the context of communication breakdown which as we have seen is a frequent and stress provoking experience for people with TBI (Bracy \& Douglas, 2005; Douglas \& Spellacy, 2000). Typically, people use communication-specific coping strategies in situations characterised by communication breakdown (Douglas et al., 2014). Productive coping strategies enhance message transfer, reduce stress and improve participation. In contrast, non-productive strategies do little to resolve problems, frequently exacerbate stress and promote social isolation. In a series of studies, our research has shown that people with TBI exhibit a pattern of communication-specific coping that deviates markedly from the norm (Friedman \& Douglas, 2005; Mitchell \& Douglas, 2011; Muir \& Douglas, 2007). We found TBI participants used significantly more non-productive coping strategies (e.g., Get angry and shout; Stop talking to the person) and significantly fewer productive strategies (Find out what the person is having trouble with; Use ex- amples) than control participants matched for age, sex and education. We also found that the ability to cope with communication breakdown was significantly associated with improved social outcome $(r=.51, p<.05)$ (Friedman \& Douglas, 2005). These findings support the functional importance of communication-specific coping. Indeed, our findings show that communication-specific coping accounts for more variance in social outcome (25\%, Friedman \& Douglas, 2005) than communication impairment (Snow et al., 1998).

Given our results, we reasoned that an intervention developed to increase productive and reduce non-productive communication-specific coping strategies would have a substantial and measurable positive impact on functional communication, stress, and emotional wellbeing for those with communication problems. Consequently, we developed a new treatment, Communicationspecific Coping Intervention (CommCope-I). We have now completed proof of concept testing using single case experimental design (SCED) with replication (Douglas et al., 2014) and a small feasibility trial $(n=13)$ (Douglas et al., in press), both of which have shown clinically and statistically significant results supporting the effectiveness of the approach. Indeed participants in both studies showed substantial improvement on measures of communication-specific coping, psychological distress and functional use of communication with improved scores maintained 1 and 3 months later.

The CommCope-I program represents an innovative approach to functional communication problems. It is systematically underpinned by treatment principles with supporting evidence from multiple disciplines and areas of practice including cognitive behavioural therapy, self-awareness training, context-sensitive communication therapy with everyday communication partners, and selfmanagement. It focuses on increasing positive behaviours rather than attempting to extinguish negative behaviours and as captured by Amanda, one of the participants, it produces results that make a difference to everyday functional language use: 'now I see what strategies I've done, and I like watching it. I feel like, 'That's me and I did it.' I didn't like going into shops, I didn't like talking on the phone . . . but I think, I definitely know there's improvements, seeing myself at the start and finishing'.

\section{Concluding Comments}

People who display poor pragmatic language competence typically have difficulty engaging in social situations, leading to uncomfortable interactions with others. Such interactions contribute to 
rejection by others and poor community integration, which can in turn contribute to negative self-concept, depressed mood, loneliness, and withdrawal from efforts to engage in community activities. In turn, withdrawal from community activities further reduces opportunities for social encounters contributing to a vicious circle of continuing and increasing social isolation, loneliness and depression. Ongoing research and treatment development efforts with a focus on improving pragmatic competence and reducing the negative effects of pragmatic impairment continue to be essential to maximise long term social gains for the large number of people with pragmatic deficits acquired as a result of brain injury.

\section{Acknowledgements}

Much of the work referred to in this presidential address reflects collaboration with a number of researchers and clinicians who I would like to thank for their much valued contributions: Sandy Barry, Christine (O'Flaherty) Bracy, Helen Bridge, Carren (Mitchell) De Maio, Melanie Drummond, Abby Friedman, Amy (Muir) Ford, Lucy Knox, Jan Mackey, Margaret Mealings, Katie Pennycuick, Margaret Pozzebon, Joanna Shorland, Pamela Snow, Leanne Togher and Jo Whiteoak. I would also like to extend my thanks to those who have so generously participated in our research and provided such important input.

\section{References}

AIHW (2007). Disability prevalence and trends. Disability series, AIHW. Bulletin 55, Dec.

Bakas, T., Kroenke, K., Plue, L.D., Perkins, S.M., \& Williams, L.S. (2006). Outcomes among family caregivers of aphasic versus nonaphasic stroke survivors. Rehabilitation Nursing, 31, 33-42.

Barry, S., \& Douglas, J. (2000). The social integration of individuals with aphasia. Advances in Speech Language Pathology, 2, 77-91.

Bayley, M., Tate, R., Douglas, J., Turkstra, L., Ponsford, J., Stergiou-Kita, M., ... On behalf of the INCOG Expert Panel (2014). INCOG guidelines for cognitive rehabilitation following traumatic brain injury: Methods and overview. Journal of Head Trauma Rehabilitation, 29, 290-306.

Benzies, K., \& Allen, M. (2001). Symbolic interactionism as a theoretical perspective for multiple method research. Journal of Advanced Nursing, 33, 541-547.

Bittner, R., \& Crowe, S.F. (2006) The relationship between working memory, processing speed and verbal comprehension and FAS performance following traumatic brain injury. Brain Injury, 21(7), 971-980.

Blumer, H. (1962). Society as symbolic interaction. In A. Rose (Ed.), Human behavior and social pro- cesses: An interactionist approach (pp. 179-192). Boston, MA: Mifflin.

Blumer, H. (1969). Symbolic interactionism: Perspective and method. Berkeley, CA: University of California Press.

Bogart, E., Togher, L., Power, E., \& Docking, K. (2012). Casual conversations between individuals with traumatic brain injury and their friends. Brain Injury, 26, 221-233.

Bracy, C., \& Douglas, J. (2005). Marital dyad perceptions of injured partners' communication following severe traumatic brain injury. Brain Impairment, 6, 112.

Burleson, B., Samter, W., \& Lucchetti, A. (1992). Similarity in communication values as a predictor of friendship choices: Studies of friends and best friends. The Southern Communication Journal, 57, 260-276.

Channon, S., \& Watts, M. (2003). Pragmatic language interpretation after closed head injury: Relationship to executive functioning. Cognitive Neuropsychiatry, 8, 243-260.

Clare, L., Nellis, S.M., Whitaker, C.J., Martyr, A., Markova, I.S., Roth, I., . . . Morris, R.G. (2012). Marital relationship quality in early-stage dementia: Perspectives from people with dementia and their spouses. Alzheimer Disease and Associated Disorders, 26, 148-158.

Cummings, L. (2005). Pragmatics: A multidisciplinary perspective, Edinburgh: Edinburgh University Press.

Cummings, L. (Ed.) (2017). Research in clinical pragmatics. In Series: Perspectives in Pragmatics, Philosophy \& Psychology (vol. 11), Cham, Switzerland: Springer-Verlag.

Dahlberg, C., Hawley, L., Morey, C., Newman, J., Cusick, C.P., \& Harrison-Felix, C. (2006). Social communication skills in persons with post-acute traumatic brain injury: Three perspectives. Brain Injury, 20, 425-435.

Douglas, J. (2010). Relation of executive functioning to pragmatic outcome following severe traumatic brain injury. Journal of Speech, Language, and Hearing Research, 53, 365-382.

Douglas, J. (2015). Placing therapy in the context of the self and social connection. International Journal of Speech-Language Pathology, 17, 199-210.

Douglas, J., \& Spellacy, F.J. (2000). Correlates of depression in adults with severe traumatic brain injury and their carers. Brain Injury, 14, 71-88.

Douglas, J., \& Togher, L. (2017). Managing acquired social communication disorders. In B. Wilson, C. van Heugten, J. Winegardner, \& T. Ownsworth (Eds.), Neuropsychological rehabilitation: The international handbook. London: Psychology Press.

Douglas, J., Bracy, C., \& Snow, P. (2007). Measuring perceived communicative ability after traumatic brain injury: Reliability and validity of the La Trobe communication questionnaire. Journal of Head Trauma Rehabilitation, 22, 31-38. 
Douglas, J., Drummond, M., Knox, L., \& Mealings, M. (2015). Rethinking social-relational perspectives in rehabilitation: Traumatic brain injury as a case study (chapter 8). In K. McPherson, B.E. Gibson, \& A. Leplege (Eds.), Rethinking rehabilitation theory (pp. 137-162). Boca Raton: CRC Press.

Douglas, J., Knox, L., De Maio, C., \& Bridge, H. (2014). Improving communication-specific coping after traumatic brain injury: Evaluation of a new treatment using single case experimental design. Brain Impairment, 15, 190-201.

Douglas, J., Knox, L., De Maio, C., Bridge, H., Drummond, M., \& Whiteoak, J. (in press). Effectiveness of communication-specific coping intervention for adults with traumatic brain injury (TBI): Preliminary results. Neuropsychological Rehabilitation. http://dx.doi.org/10.1080/09602011.2016.1259114

Douglas, J., O'Flaherty, C., \& Snow, P. (2000). Measuring perception of communicative ability: The development and evaluation of the La Trobe Communication Questionnaire. Aphasiology, 14, 251-268.

Duck, S. (1988). Relating to others. Milton Keynes: Open University Press.

Eloniemi-Sulkava, U., Notkola, I.L., Hamalainen, K., Rahkonen, T., Viramo, P., Hentinen, M., .. . Sulkava, R. (2002). Spouse caregiver perceptions of influence of dementia on marriage. International Psychogeriatrics, 14, 47-58.

Friedman, A., \& Douglas, J. (2005). Social participation and coping with communication breakdown following severe traumatic brain injury. Brain Injury, Supplement, 6, 50-51.

Galski, T., Tompkins, C., \& Johnston, M. (1998). Competence in discourse as a measure of social integration and quality of life in persons with traumatic brain injury. Brain Injury, 12, 769-782.

Gill, C., Sander, A., Robins, N., Mazzei, D., \& Struchen, M. (2011). Exploring experiences of intimacy from the viewpoint of individuals with traumatic brain injury and their partners. Journal of Head Trauma Rehabilitation, 26, 56-68.

Godwin, E., Chappell, B., \& Kreutzer, J. (2014) Relationships after TBI: A grounded research study. Brain Injury, 28, 398-413.

Grawburg, M., Howe, T., Worrall, L., \& Scarinci, N. (2013). Third-party disability in family members of people with aphasia: A systematic review. Disability and Rehabilitation, 35, 1324-1341.

Hilari, K., Northcott, S., Roy, P., Marshall, J., Wiggins, R.D., Chataway, J., \& Ames, D. (2010). Psychological distress after stroke and aphasia: The first six months. Clinical Rehabilitation, 24, 181-190.

Hyder, A. (2007). The impact of traumatic brain injuries: A global perspective. NeuroRehabilitation, 22, 341353.

Karlovits, T., \& McColl, M. (1999). Coping with community reintegration after severe brain injury: A description of stresses and coping strategies. Brain Injury, $13,845-861$.
Lefebvre, H., Cloutier, G., \& Levert, J. (2008). Perspectives of survivors of traumatic brain injury and their caregivers on long-term social integration. Brain Injury, 22, 535-543.

Mackey, J., Sloan, S., Starritt, N., \& Douglas, J. (2007). Improving social outcomes following brain injury through development of confident communication skills. Brain Impairment, 8, 207-208.

McDonald, S. (1993). Pragmatic language skills after closed head injury: Ability to meet the informational needs of the listener. Brain and Language, 44, 28 46.

Mead, G.H. (1934). Mind, self and society: From the standpoint of a social behaviorist. Chicago: University of Chicago Press.

Mitchell, C., \& Douglas, J. (2011). Coping with communication breakdown: A comparison between adults with severe TBI and healthy controls. Brain Impairment, 12, Supplement, 41.

Muir, A., \& Douglas, J. (2007). Coping with communication breakdown after severe traumatic brain injury. Brain Impairment, 8, 83.

Nussbaum, J. (1994). Friendship in older adulthood. In M.L. Hummert, J.M. Wiemann, \& J.F. Nussbaum (Eds.), Interpersonal communication in older adulthood: Interdisciplinary theory and research (pp. 209-225). California: Sage Publications, Inc.

O'Flaherty, C., \& Douglas, J. (1997). Living with cognitive-communicative difficulties following traumatic brain injury: Using a model of interpersonal communication to characterise the subjective experience. Aphasiology, 11, 889-911.

Oliver, C. (2012). The relationship between symbolic interactionism and interpretive description. Qualitative Health Research, 22, 409-415.

Olver, J.H., Ponsford, J.L., \& Curran, C.A. (1996). Outcome following traumatic brain injury: A comparison between two and five years after injury. Brain Injury, 10, 841-848.

Paterson, J., \& Stewart, J. (2002). Adults with acquired brain injury: Perceptions of their social world. Rehabilitation Nursing, 27, 13-18.

Perkins, M. (2005). Pragmatic ability and disability as emergent phenomena. Clinical Linguistics and Phonetics, 19, 367-377.

Perlman, D. (2008). Intimate relationships. New York: McGraw-Hill.

Plummer, K. (2000). Symbolic interactionism in the twentieth century. In B. Turner (Ed.), The Blackwell companion to social theory (pp. 193-222). Malden, MA: Blackwell.

Pound, P., Gompertz, P., \& Ebrahim, S. (1998). A patientcentred study of the consequences of stroke. Clinical Rehabilitation, 12, 338-347.

Pozzebon, M., Douglas, J., \& Ames, D. (2016). Spouses' experience of living with a partner diagnosed with a dementia: A synthesis of the qualitative research. International Psychogeriatrics, 537-556. doi:10.1017/S1041610215002239. 
Rogge, R., \& Bradbury, T. (1999). Till violence does us part: The differing roles of communication and aggression in predicting marital outcomes. Journal of Consulting \& Clinical Psychology, 67, 340-351.

Shorland, J., \& Douglas, J. (2010). Understanding the role of communication in maintaining and forming friendships following traumatic brain injury. Brain Injury, 24, 569-580.

Snow, P., \& Douglas, J. (2017). Psychosocial aspects of pragmatic disorders. In L. Cummings (Ed.), Research in clinical pragmatics, series: Perspectives in pragmatics, philosophy \& psychology (vol. 11, pp. 617-649). Cham, Switzerland: Springer-Verlag.

Snow, P., Douglas, J., \& Ponsford, J. (1997). Conversational assessment following traumatic brain injury: A comparison across two control groups. Brain Injury, 11, 409-430.

Snow, P., Douglas, J., \& Ponsford, J. (1998). Conversational discourse abilities following severe traumatic brain injury: A longitudinal follow-up. Brain Injury, 11,911-935.

Struchen, M., Clark, A., Sander, A., Mills, M., Evans, G., \& Kurtz, D. (2008). Relation of executive functioning and social communication measures to functional outcomes following TBI. Neurorehabilitation, 23, 185-198.

Struchen, M., Pappadis, M., Sander, A., Burrows, C., \& Myszka, K. (2011). Examining the contribution of social communication abilities and affective/behavioral functioning to social integration outcomes for adults with traumatic brain injury. Journal of Head Trauma Rehabilitation, 26, 30-42.

Togher, L., Wiseman-Hakes, C., Douglas, J., StergiouKita, M., Ponsford, J., Teasell, R., ... Turkstra On behalf of the INCOG Expert Panel (2014). INCOG Recommendations for management of cognition following TBI Part IV: Cognitive communication. Journal of Head Trauma Rehabilitation, 29, 353368.

Turkstra, L., McDonald, S., \& Kaufmann, P. (1995). Assessment of pragmatic communication skills in adolescents after traumatic brain injury. Brain Injury, 10, 319-345.

Wang, Y., Kent, R., Duffy, J., \& Thomas, J. (2005). Dysarthria in traumatic brain injury: A breath group and intonational analysis. Folia Phoniatrica et Logopaedica, 57, 59-89.

Whiteneck, G., Charlifue, S., Gerhart, K., Overholser, J., \& Richardson, G. (1992). Quantifying handicap: A new measure of long-term rehabilitation outcomes. Archives of Physical Medicine and Rehabilitation, 73, 519-526.

Willer, B., Ottenbacher, K., \& Coad, M. (1994). The community integration questionnaire: A comparative examination. American Journal of Physical Medicine and Rehabilitation, 73, 103-111.

Willmott, P. (1987). Friendship networks and social support. London: Policy Studies Institute. 